\title{
Practice Based Education Illustrated by the Problem of Construction of Welded Lift frame for Handling Amelioration Tubes
}

\author{
P. Cyrus \\ University of Hradec Kralove, Czech Republic
}

A. Slabý
University of Hradec Kralove, Czech Republic

\begin{abstract}
This paper describes the structural design of the lifting frame designed for handling ameliorating waste concrete pipes. It demonstrates one task solved in the subject Construction practice directed for the students studying specialization: Teachers of technical education at the University of Hradec Kralove. In order to determine the stress distribution at the lifting frame, a theoretical analysis of the problem was performed. 3D computer model of the lifting frame was created subsequently. Computer analysis of generated 3D models was performed using the finite element method and the software Autodesk Inventor. The article presents some of the results obtained through the mentioned software such as the distribution of equivalent stress in the individual sections of the frame and the corresponding deformation of the expected static load capacity.
\end{abstract}

KEYWORD: Construction problem; structural analysis; computer model; stress analysis of frame.

\section{INTRODUCTION}

The use of CAD systems in mechanical engineering is nowadays inevitable. Therefore, the integration of teaching and application of CAD systems in to the study programs of preparation for future technicians has become obvious. CAD systems are integrated in several subjects of the study, mainly technical drawing, machine parts, design exercises, machines, devices and equipment. Furthermore, these systems are enriched by other additional specialized modules are also used in some other subjects such as Strength and elasticity and others. In this last mentioned course are solved various problems emanating from practice. And here is the application of CAD systems also inevitable.

This article in further parts describes one selected design task - solutions of the construction of lifting mobile frame placed on special lorries and intended/ designed for handling ameliorative waste concrete pipes. This is a sample of problem taken from the subject Design/construction practice and it shows the role of the subject Design practice, which is directed for students and teachers of technical subjects University of Hradec Kralove.

In solving such problems from engineering practice it is necessary to make use the knowledge and skills acquired in other subjects of the study programs such as Technical mechanics, Strength and Elasticity, Machine parts, material and technologists and others. Furthermore, a solution with the help of CAD systems is crucial, customary and necessary.

\section{DESCRIPTION OF THE PROBLEM}

Laying amelioration large-diameter concrete pipes into the soil requires special procedures and making use of the appropriate mechanization. These include handling during loading, transporting and stacking tubes into the place suitable for storage and subsequent laying the pipes in the trench. Due to the large mass of concrete pipes (approximately around $400 \mathrm{~kg}$ ), it is necessary to use a mobile crane for handling. The concrete pipe is fitted inside cylindrical surface using a special tool and subsequently is loaded using a crane vertically on storage truck. Folding of the truck is carried out using the same tool (device). Inserting of a concrete pipe into the trench in the ground was in the past arranged by means of the welded chain that was lead through the inside of the tube and suspended at the hook of the crane as shows the following Figure 1.

The pipe had first been moved to a horizontal position on the ground. Consequently, it is necessary to adjust the chain so that the tube was in suspension in a horizontal position. Concrete pipes could be relatively easily damaged during this manipulation. Handling also requires a certain amount of care and experienced staff. 
Specially designed lifting frame for the mobile crane may serve as another option of handling concrete pipes. This lifting frame is the main output of here investigated problem.

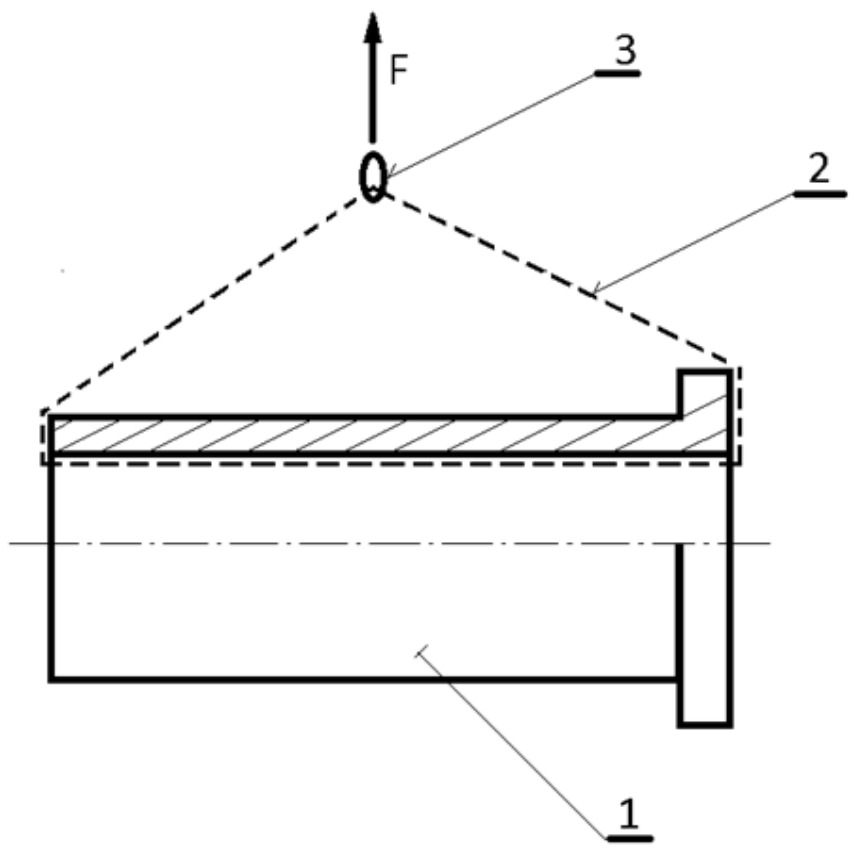

Figure1. 1-concrete tube, 2-welded chain, 3-caliper

The mobile crane is displayed on Figure 2 on the right and the mounted lifting frame in the middle of the figure. Lifting frame is hanging on chain slings and connected by a crane hook with rope. On the left of the image is situated upright the concrete pipe.

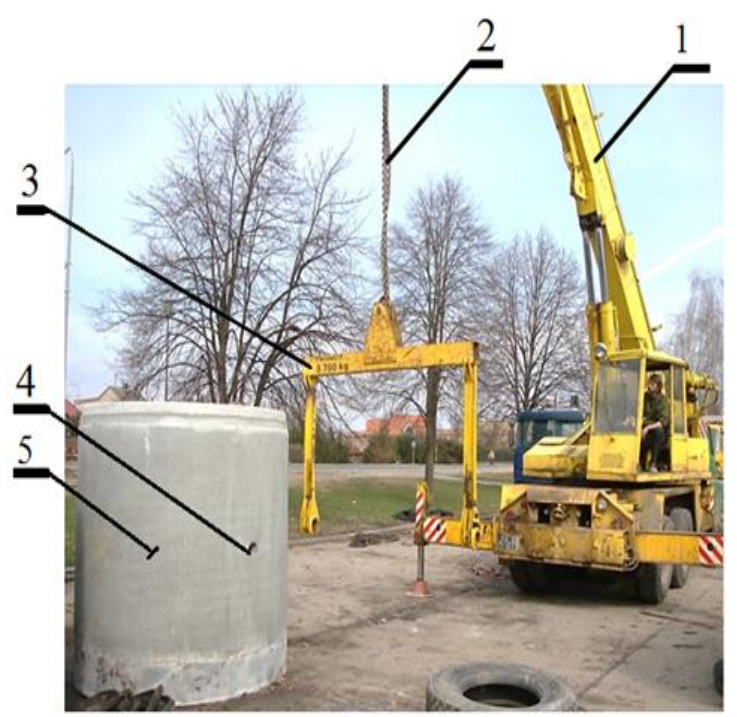

Figure 2. View of the crane with lifting frame and tube. 1-mobile crane, 2-chain hinge 3-lifting frame, 4-concrete pipe, 5 -circular hole in the pipe, 6-circular opening in the housing frame member

Now it is necessary to lift the concrete tube, (item 4 of above figure) and subsequently rotate it by the angle of $90^{\circ}$ which is suitable for joining it to the trench (pipeline). The connection of pipe 4 on Figure 2 with a vertical leg lifting frame 3 is established by two pins (not shown). Pins are inserted into one end of the housing openings at the end of the vertical arms of the lifting frame and the other end to the side opening in the tube. Pins are secured against axial displacement (movement). After lifting tubes upright by the crane the pipe rotates around the pins by the angle of $90^{\circ}$ to a horizontal position and is ready for placement into the trench.

\section{MATERIAL AND METHODS}

The 3D computer model of the lifting frame appropriate to offered design solution is shown on the Figure 3. The lifting frame is composed of a beam 1 and the two vertical arms 2. Crossbar 1 is designed and constructed of the two cylindrical sections U 200 CSN 425570-11373.0 welded to each other, forming a closed profile in the shape of a rectangle. Right and left arms 2 and 3 are made from rolled I 120 CSN 425550-11370.0.

Tubular housing 4 are welded to the arms 2 and 3, the connection of the parts 2 and 4 is reinforced by three ribs 5. Pin 6 together with face plates 7 , are used for fixing the chain suspension.

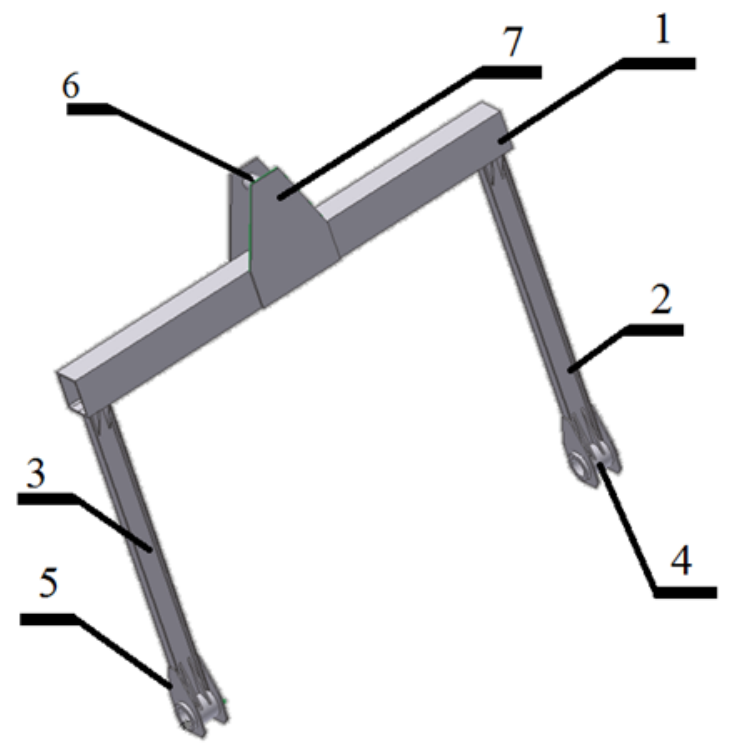

Figure 3. Model of the lifting frame.

1-crosspiece, 2,3 - vertical arms, 4-housing, 5-rib, 6-pin, 7-face plates

The important part of the analysis is analysis of the forces. Analysis of the load is illustrated in the following Figure 4. 


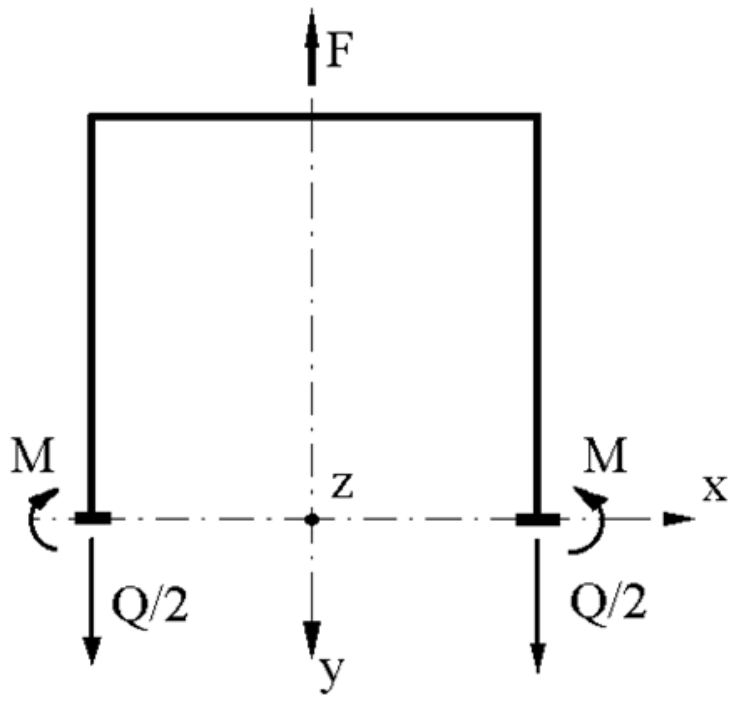

Figure 4. Forces/load analysis. Q -load of the frame equals $57000 \mathrm{~N}$.

Symbols in Figure5 have the following meaning: $\mathrm{F}$ - the total force required to lift the pipe. It holds $\mathrm{F}=\mathrm{Q}+\mathrm{G}_{1}$, where $\mathrm{Q}$ - the weight of the tube and $\mathrm{G}_{1}$ - weight of the lifting frame, $\mathrm{Q}=\mathrm{m}_{\mathrm{t}}$. $\mathrm{g}$ where $\mathrm{m}_{\mathrm{t}}$ is the mass of the pipe and $\mathrm{q}$ - gravitational acceleration. Finally $\mathbf{M}-$ is moment power couple and it holds $\mathrm{M}=\mathrm{a} \cdot \mathrm{Q} / 2$ and $\mathrm{a}-$ is the distance between the mounting bolt in the tube and the middle of the arm of the frame.

\section{RESULTS}

The lifting frame is structurally designed for the expected load $57000 \mathrm{~N}$. After the theoretical calculations (Cyrus \& Zajic, Shigley, Mischke \& Nas 2008, Puchmajer 2001), the frame was subjected to computer analysis in terms of its strength and stiffness. Computer program Autodesk Inventor Professional 11 (Autodesk Inventor 2010).

ANSYSS technology was used for analysis. The results obtained by strength and stiffness analysis are shown at Figure 3. and Figure 4 (Autodesk Inventor 2010).

The results computer analysis of the distribution of equivalent stress in different parts of the frame is shown on Figure 5. Tension in the individual parts of the structure differ (are variable) and variety of tension is identified (visualized) by different colors. Zero tension is colored blue, the maximum tension is marked by the red color. Individual colors corresponding to the tension values as shown in the color spectrum measure bar seen at Figure 5, on the left. The maximum tension is on the outside and inside of the vertical arms (see I profile of the arms) and is depicted by yellow color. Yellow color corresponds, as shown in standard color measure bar (shown on the left of Figure 5), to approximately 90 $\mathrm{MPa}$ of stress. This maximum tension is less than $\sigma_{\text {allowed }}$ (allowed tension). The value for the discussed material is equal to $110 \mathrm{MPa}$. We can come to the conclusion that the frame suits (complies) from the strength point of view.

Stiffness analysis of the lifting frame is shown on Figure 6. Here are shown deformations in the frame in various parts of the construction by different colors. The color varies from blue to red (see standard color measure bar on the left of the Figure 6. Color information is unfortunately suppressed due to black and white print of the article.

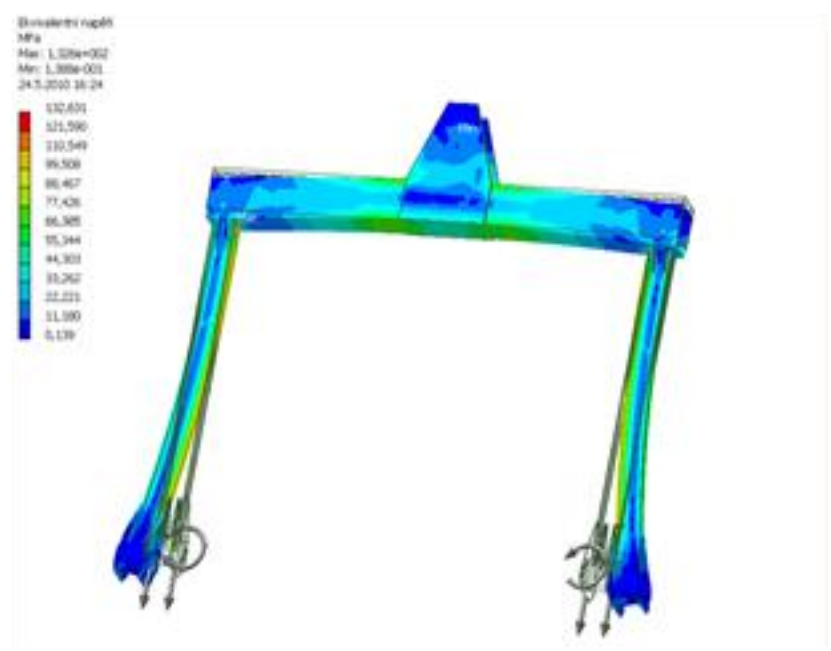

Figure 5. Results of Stress Analysis of lifting frame.

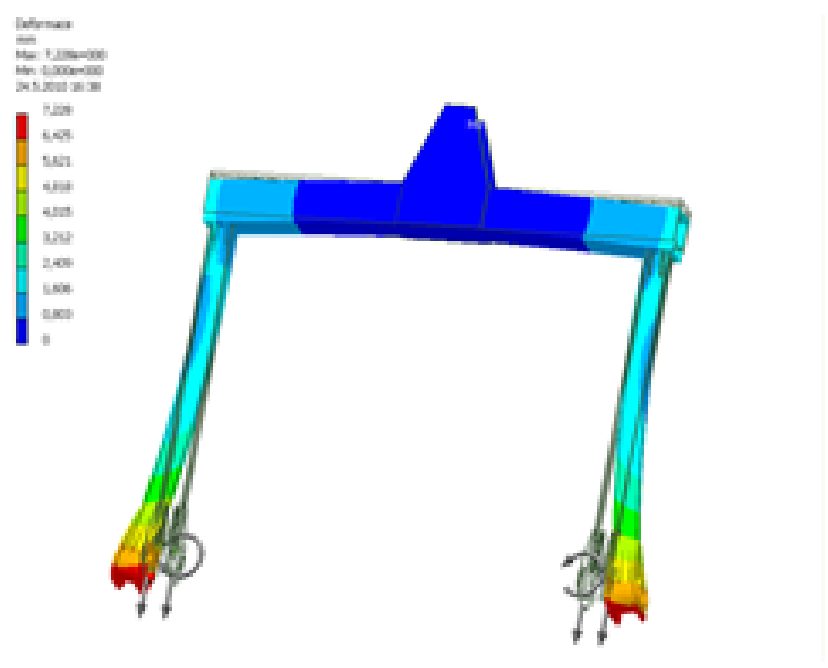

Figure 6. Results of Stiffness Analysis of lifting frame.

The maximum deflection appears at the end of the vertical arm at the pivot connecting the arm to the pipe. The value of deformation is approximately $6.50 \mathrm{~mm}$. This value of calculated deformation is important. It ensures the safety coupling between the frame and the concrete pipe to prevent the ejecting of the pin from the hole in the tube. Value of deformation suits for the defined purpose. As Figure 5 and Figure 6 are shown in grayscale, due to impossibility of printing the proceedings in the color, figures enable to read only wanted changes in stress and deformation of the lifting frame. It should also be noted that if a copy of the analysis is displayed in grayscale color with red and blue 
transform to the similar shade near the black. For a detailed determination of the searched variables (and of course in the process of education) it is better to work with color information.

\section{DISCUSSION AND CONCLUSION}

The problem discussed in article demonstrates one application of CAD systems in structural engineering practice. Such tasks allow students to understand better the solution of technical problems in the design of new facilities. Students also recognize the need to manage various technical disciplines to be able to enter the necessary values and parameters and check on calculations and analyzes achieved by computer programs based on data obtained from CAD systems designed components in 3D parametric form.

Results of strength and stiffness analysis of the frame achieved with the help of software Autodesk Inventor shown in Figure 5 and Figure 6 visualize the distribution of the equivalent stress and strain in the different cross sections of the frame. The results of computer analysis shown at Figure 5 and Figure 6 correspond to the results obtained by classical methods of calculation of stress and deformation inside the frame. We can summarize that the frame suits both in terms of strength and stiffness conditions.

Solution of similar technical tasks under the guidance of experienced professors motivates students for technical creative work. It also increases the interest and diligence engineering students to successfully solving problems.

\section{REFERENCES}

[1] Cyrus P. \& Zajic B. Pevnostní a tuhostní analýza svařované konstrukce jeřábového prrípravku zdvihacího rámu pro manipulaci s betonovými trubkami. Unpubl.

[2] Autodesk Inventor - referenční manuál

[3] Shigley,J.E., Mischke,R,Ch. \& nas.R.G.Konstruování strojních součástí. Brno. VUTIUM 2010. ISBN 978-80214-2629-0.

[4] Puchmajer,P. Pružnost pevnost. Praha. ČVUT 2001. ISBN 80-01-02059-2. 